\title{
A WHOLE-FIELD INTERFEROMETRIC SCHEME FOR MEASURING STRAIN AND FLOW RATES OF GLACIER AND OTHER NATURAL SURFACES
}

\author{
By Gary Cloud and Edgar Conley \\ (Department of Metallurgy, Mechanics and Materials Science, Michigan State University, \\ East Lansing, Michigan 48824, U.S.A.)
}

\begin{abstract}
The flow of glacier ice is mapped using high-resolution photography and non-coherent-light speckle interferometry. Young's fringe patterns result when a double-exposed photoplate image of the straining surface is illuminated by a narrow beam of coherent light. Geometry gives a relationship between the ice surface displacement vector and the interference fringe patterns. This displacement vector is corrected for rigid-body (camera) movement and projected onto the ice surface using topological maps. The strain during the time-lapse interval is thus known. Comparison with data acquired by surveying techniques at Nisqually Glacier, Washington, U.S.A., is limited because of small overlap of the surface studied. In the areas for which results can be compared, our experiments yield a flow of $0.6 \mathrm{~m} / \mathrm{d}$ where conventional methods yield about $0.4 \mathrm{~m} / \mathrm{d}$.
\end{abstract}

RÉsumÉ. Un montage interférométrique de terrain pour mesurer les vitesses de deformation et d'écoulement des glaciers et d'autres surfaces naturelles. On cartographie l'écoulement d'un glacier avec des photographies à haute résolution et une interférométrie à moucheture en lumière non cohérente. Des franges de Young s'observent lorsque une image double exposition de la surface en déformation est éclairee par un court éclair de lumière cohérente. La géométrie donne une relation entre le vecteur déplacement de la surface de la glace et les franges d'interférence. Ce vecteur déplacement est corrigé en fonction du mouvement de corps fixe (camera) et projecté sur la surface de la glace à l'aide de cartes topologiques. La déformation durant l'intervalle des temps d'exposition est alors connue. La comparaison avec les données acquises par des techniques classiques au Nisqually Glacier, Washington, U.S.A., est limitée à cause de faible recouvrement des surfaces étudiées. Dans les zones où les résultats peuvent être comparés, nos expériences nous conduisent à une vitesse de $0,6 \mathrm{~m} /$ jour où les méthodes conventionnelles donnaient environ $0,4 \mathrm{~m} /$ jour.

ZuSAMmENFASSUNG. Ein neues interferometrisches Ganzfeld-System zur Messung von Spannungs- und Fliessraten auf Gletscher- und anderen natürlichen Oberflächen. Die Fliessbewegung von Gletschereis wird durch hochauflösende Photographie und Interferometrie mit nicht-kohärentem Licht erfasst. Bei der Beleuchtung einer doppelt belichteten photographie der sich verformenden Oberfläche mit einem scharf gebündelten Strahl kohärenten Lichtes ergeben sich Young'sche Figuren. Geometrisch lassen sich Beziehungen zwischen dem Verschiebungsvektor der Eisoberfläche und dem entstehenden Fransenmuster herleiten. Der Verschiebungsvektor wird hinsichtlich eventueller Bewegungen eines starren Körpers (Kamera) korrigiert und mit Hilfe topologischer Karten auf die Gletscheroberfläche projiziert. Die Deformation während des Zeitintervalls ist damit bekannt. Der Vergleich mit Daten die mit konventionellen Methoden am Nisqually Glacier, Washington, U.S.A., gewonnen wurden, ist infolge der geringen Uberlappung der beiden untersuchten Oberflächenstücke begrenzt. Im Überlappungsgebiet beider Methoden ergaben unsere Versuche einen Fluss von 0,6 $\mathrm{m}$ pro Tag, während die konventionelle Messung $c .0,4 \mathrm{~m}$ pro Tag lieferte.

\section{INTRODUCTION}

This paper reports on the application of non-coherent speckle photography and coherent optical processing (Cloud and others, 1980) to map small displacements on various rock, earth, and ice surfaces. Briefly, this optical technique requires a high-resolution double-exposed photographic image of the surface of interest: the first image is taken before displacement; the second after. The photographic image is then analyzed with coherent light as described below. 
Since the method requires only optical access to the straining surface, other applications include volcanic rock stability, mine-wall strains, and perhaps tectonic plate strains.

\section{METHOD}

The experiments, conducted at Michigan State University and at the Nisqually Glacier site (Fig. 1) during September 1981, were organized in four phases:

First, speckle patterns were obtained using non-coherent light from a partially gravelled parking lot located near the Michigan State University Engineering Building. Although this surface seems quite different from that of an ice field, the variable roughness and random largescale patterns (e.g. recent tire tracks) resulted in a fair approximation for technique development. The parking lot was photographed from a perch about $20 \mathrm{~m}$ above grade; the surface extending from 150 to $200 \mathrm{~m}$ horizontally from the camera location.

As noted, the surface in question must be moved or displaced slightly in order to produce Young's fringe patterns during final processing of the double-exposure high-resolution photograph. The camera back was rotated a small amount, approximately 20 minutes of arc, between exposures in order to create an artificial field displacement.

During this phase trade-offs between experimental parameters were explored. Investigated factors include $f$-stop, shutter speed, resolution, film speed, focal length, developing technique, etc.

Phase two began with the determination of useful focal length, proper exposure, developing time, etc., for actual glacier conditions. During these tests the camera back was again rotated between exposures in order to create the required artificial field displacement.

Third, time-lapse, double-exposure photographs of the upper elevations of the Nisqually Glacier (Fig. 2) were taken from several viewpoints, each within one kilometer of the terminus. The time interval between exposures was $24 \mathrm{~h}$. The $24 \mathrm{~h}$ tests were started in the morning since an oblique sun angle on the south-facing Nisqually Glacier helps to delineate surface roughness.

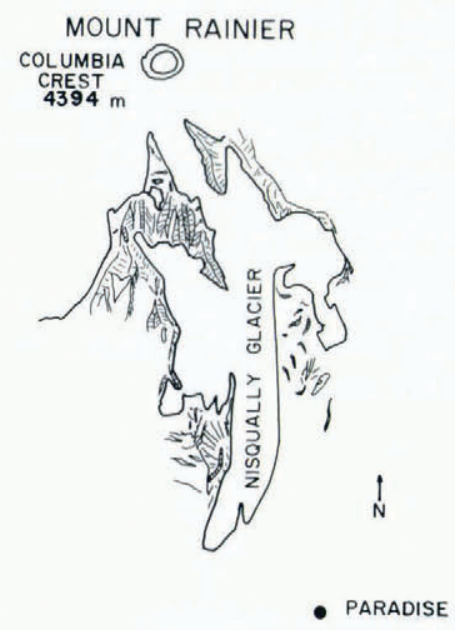

Fig 1. Nisqually Glacier, Rainier National Park, Washington. 


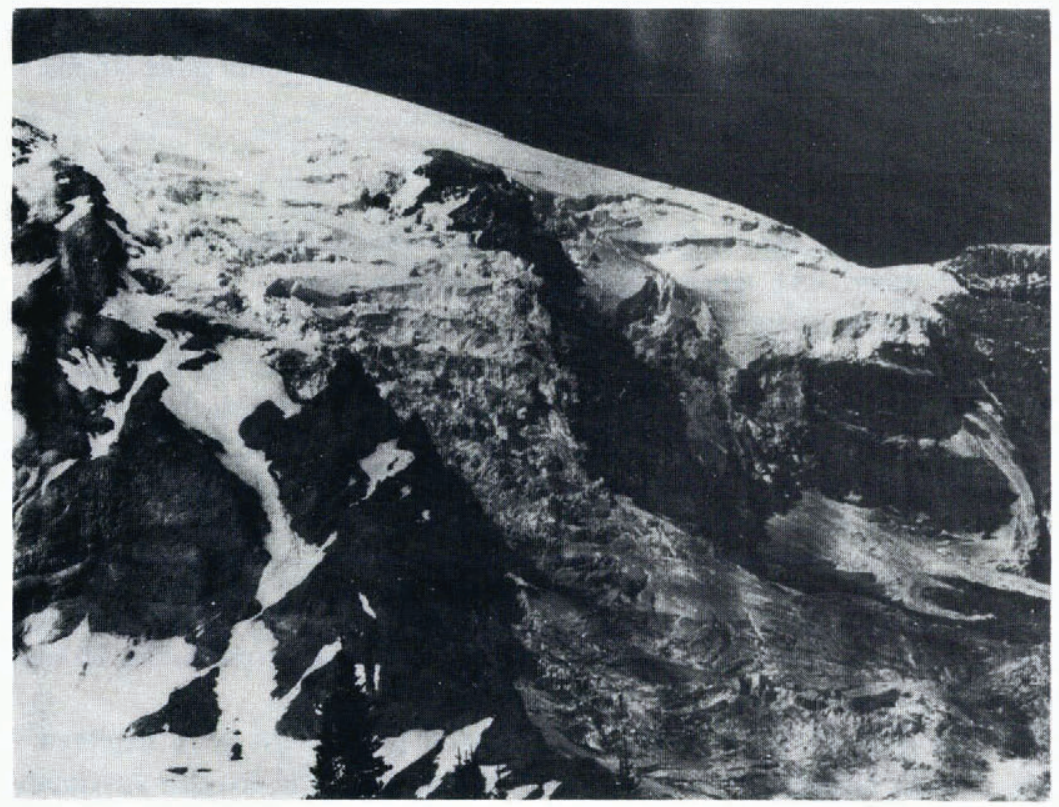

Fig 2. View of upper elevations of Nisqually Glacier.

A full $24 \mathrm{~h}$ between exposures results, in addition, in a nearly identical sun angle which increases precision. During this phase, the camera was first mounted on a tripod and then on a large rock in order to minimize camera movement.

Fourth, the data plates were analyzed in a coherent optical system at Michigan State University to obtain Young's fringe patterns which are indicative of the flow vector field.

Extraction of surface displacements from the double-exposed photoplates was accomplished as follows:

(1) Spacing and orientation of Young's fringes were measured relative to vertical. Corresponding points were then located on the glacier surface using topological maps.

(2) The ice surface normals were determined at these points.

(3) The magnitude and direction of any rigid body motion (i.e. camera movement) was detected through microscopic examination of the plate. (Fixed objects appearing on the horizon, such as large boulders resting on the bare rock surface, were useful for this.) The rigid-body reference point was then located on the topological map.

(4) A computing routine subtracted appropriately scaled rigid-body motion from each point on the plate where fringe patterns were logged, and then it projected the resulting displacement vector onto the glacier surface.

\section{RESULTS}

During phase one it was found that small rotations of the camera back about the center of the film produced circular rings of classical speckle pairs which appear superimposed on the 
parking lot surface. When scanned by a narrow beam of coherent light, the resulting Young's fringe patterns appeared to rotate and become more fine as the film was scanned from the center outward. This behavior was exactly as expected for rigid-body rotation.

A similar result was produced during the second phase by rotating the camera back with the glacier surface as the object.

The first $24 \mathrm{~h}$ double exposures of the glacier surface did not yield results because of apparent large camera movement. This problem was reduced by mounting the camera on a large rock. The desired speckle pairs were produced on large areas of the glacier surface image.

Typical Young's fringes obtained from the glacier photoplate can be seen in Figure 3 . These were obtained by illuminating small areas (nine in all) of the double-exposed glass-plate transparency reproduced by enlargement in Figure 4. These Young's fringe patterns have not been retouched or subjected to any of the common speckle reduction procedures. They do appear to contain substantial "noise", of course. Much of this optical noise can be eliminated by well-known methods.

Figure 5 is a plan view of the Nisqually Glacier surface showing the location, relative magnitude and direction of ice displacement $S_{\text {mag }}$ in meters/day for nine points on the glacier surface. Tabulated results are also shown for the three component directions.

It should be noted that since optical data-processing does not reveal a sign, assumptions were made regarding the direction of movement. First, it was assumed that ice flows downhill. The second assumption, that of rigid-body motion direction, is somewhat less clear intuitively. Two
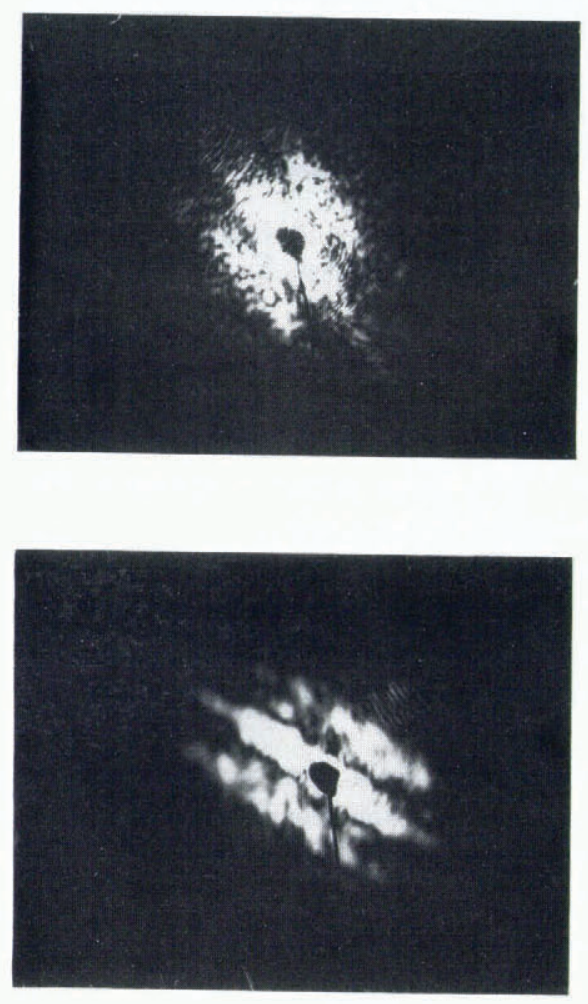

Fig. 3. Young's fringe patterns generated by passing laser light through two points on high-resolution double-exposure negatives of Nisqually Glacier. 


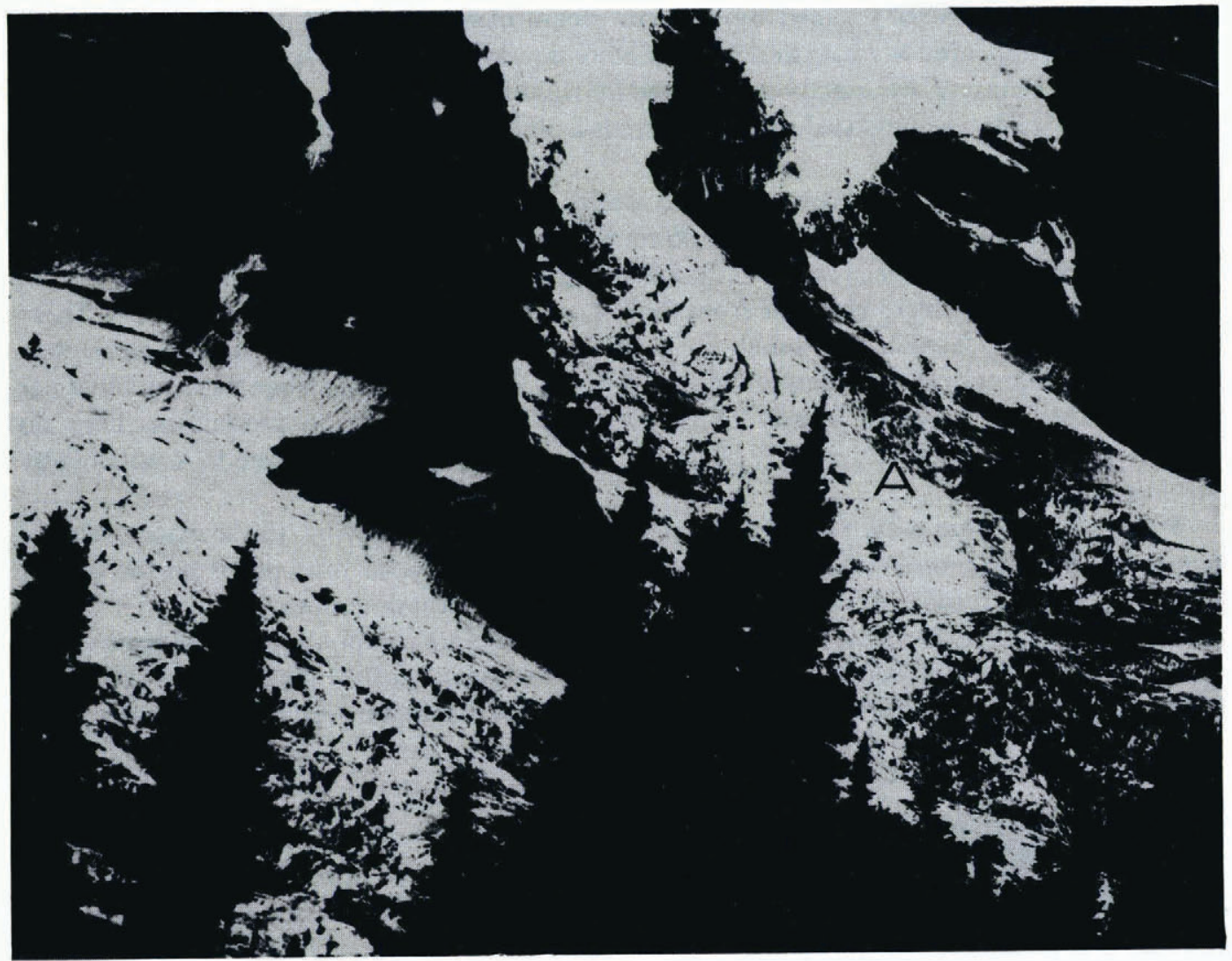

Fig. 4. Englargement of high-resolution double-exposed speckle plate of Nisqually Glacier. Note/ne image structure which creates speckle data is not reproduced except in a few limited areas such as near point A.

quite different plots such as shown in Figure 5 could be generated depending on the choice of direction for the rigid-body movement. We give Figure 5 as simply the most reasonable choice since the alternative computation gives displacements of 3 to 4 times greater magnitude. The simultaneous use of two cameras would eliminate this ambiguity.

Points 7 and 8 in Figure 5 roughly correspond to points tracked by conventional methods over a two-year period and reported by Hodge (1974). The 1973 report gives displacement in the range of 0.3 to $0.4 \mathrm{~m} / \mathrm{d}$ and apparently increasing with time. Figure 5 shows a rate of $0.6 \mathrm{~m} / \mathrm{d}$ for September 1981. At this early stage of the program such correspondence is highly satisfactory.

The following summary conclusions can be drawn:

1. Motion of a natural surface illuminated by non-coherent light can be evaluated by Young's fringe patterns produced from double-exposure high-resolution photoplates.

2. Analysis of typical fringe patterns from the $24 \mathrm{~h}$ tests, such as shown in Figure 3, yields the displacement vector map (Fig. 5) for the glacier surface.

3. The displacement vectors determined to date agree with the limited field data previously reported. 


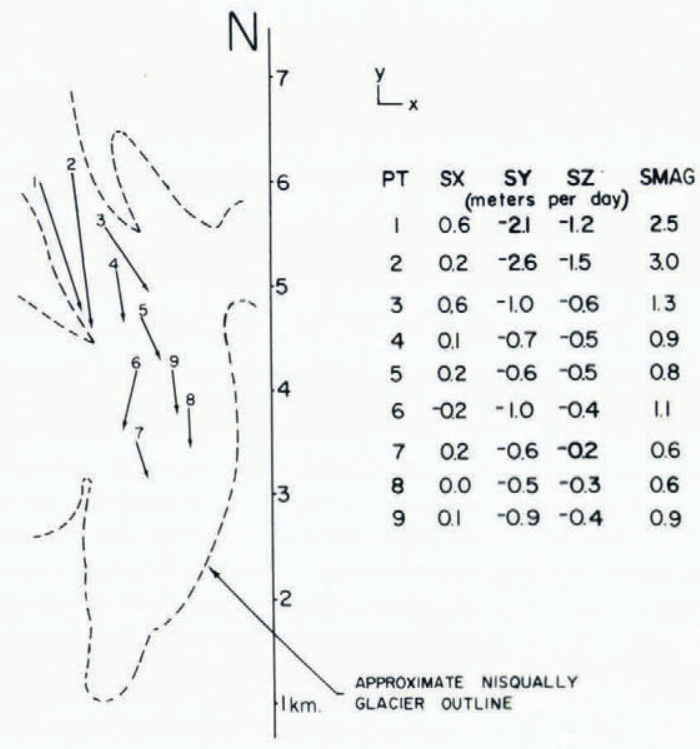

Fig 5. Surface displacement vector map, plan view. Note surface displacement vectors have length $\left(S_{x}^{2}+S_{y}^{2}+S_{z}^{2}\right)^{1 / 2}$, not $\left(S_{x}^{2}+S_{y}^{2}\right)^{1 / 2}$ as would be seen when viewing in the negative $Z$ direction.

\section{ACKNOWLEDGEMENT}

This research was supported by the National Science Foundation under grant No. CME-8008273. The authors are grateful to Mr Eric Burgoon for his insight, patience and diligent efforts in field and laboratory. The staff persons at Mount Rainier National Park have been kind and helpful, and we are appreciative.

MS. received 24 August 1982 and in revised form 21 February 1983

\section{REFERENCES}

Cloud, G., and others. 1980. Noncoherent-light speckle photography for measurements of fluid velocity fields, [by] G. Cloud, R. Falco, R. Radke, J. Peiffer. Proceedings of the Society of Photo-Optical Instrumentation Engineers, Vol. 243, p. 150-57

Hodge, S. M. 1974. Variations in the sliding of a temperate glacier. Journal of Glaciology, Vol. 13, No. 69, p. 349-69. 